\title{
Psychological changes correlated with thalamotomy site
}

\author{
M. F. JURKO AND O. J. ANDY \\ From the Department of Neurosurgery, University of Mississippi Medical Center, \\ Jackson, Mississippi, 39216, U.S.A.
}

SUMMARY The effects of surgically placed thalamic lesions on cognitive skills, as measured bof psychological tests, are dependent upon the nature of the skill and the site of the lesion. Lesions within the limits of the centrum medianum nucleus produce few deficits, whereas lesions outside it $\vec{\odot}$ limits result in deficits for a greater number of skills. In general, the more complex skills revealect more impairment and the deficits were long lasting.

The function of the thalamus in relation to cognition, as reflected by psychological tests, was evaluated in patients treated by thalamotomy for Parkinsonism, seizure, and pain disorders.

The psychological tests are considered under four categories and correlated with lesions placed within and outside the limits of the centrum medianum nucleus. The age of patients with Parkinson's disease ranged from 37 to 72 years and those with seizure and pain disorders from 20 to 62 years.

\section{METHOD}

SURGICAL PROCEDURE Lytic lesions were made stereotaxically under local anaesthesia. A 20 gauge barrel electrode with a 3 to $4 \mathrm{~mm}$ non-insulated tip was inserted into the diencephalon through a frontal burr hole at an angle of approximately 40 to $45^{\circ}$. Electrical stimulation followed by an electrolytic lesion was performed as previously described (Andy, Jurko, and Sias, 1963; Andy, 1966). The atlas of Schaltenbrand and Bailey (1959) was used to determine placement of the electrodes.

ADMINISTRATION OF THE PSYCHOLOGICAL TESTS The standard method of administration supplied with each test was used. Testing was done several days preoperatively, on the fifth postoperative day, and as late as the second postoperative year.

TEST RESULTS AND LESION SITE The data were analysed by plotting results derived from each of the tests in relation to the locus of the lesion. Scatter grams were used for plotting the lesions on horizontsid planes through the thalamus at the level of centrum medianum nucleus $(+3.5 \mathrm{~mm})$. This plistie was chosen because the maximum size of the lesmon was at that approximate location of the thalamis and the greater variability in these patients was in relation to the mediolateral and frontopostegos positioning of the lesion. The statistics used, where applicable, were the $2 \times 2 \chi^{2}$ test, and the two-taref binomial expansion test.

\section{RESULTS}

SPATIAL-MOTOR PERFORMANCE (BENDER VISUA@ MOTOR GESTALT TEST) Changes in the patient postoperative drawings (Bender, 1946) were scored on the basis of 10 variables. These varp ables were as follows. (1) Pressuring Designs drawn with increased pencil pressure. (z) Dashing Dashes substituted for dots or loops. (3) Simplification Angles and wavy lines flaf tened. (4) Side edging The drawings placed along the vertical edge of the paper. (5) $T$ o edging The drawings placed along the top edge of the paper. (6) Expansion-compression The designs spread widely on the page or draw on one-half page or less. (7) Retrace Ret drawing of a previously made line. (8) Pei severation Repetition of units in a design with total disregard of design limits. (9) Collisian Two or more designs encroaching on one another. (10) Rotation A 90 to $180^{\circ}$ shift in the 


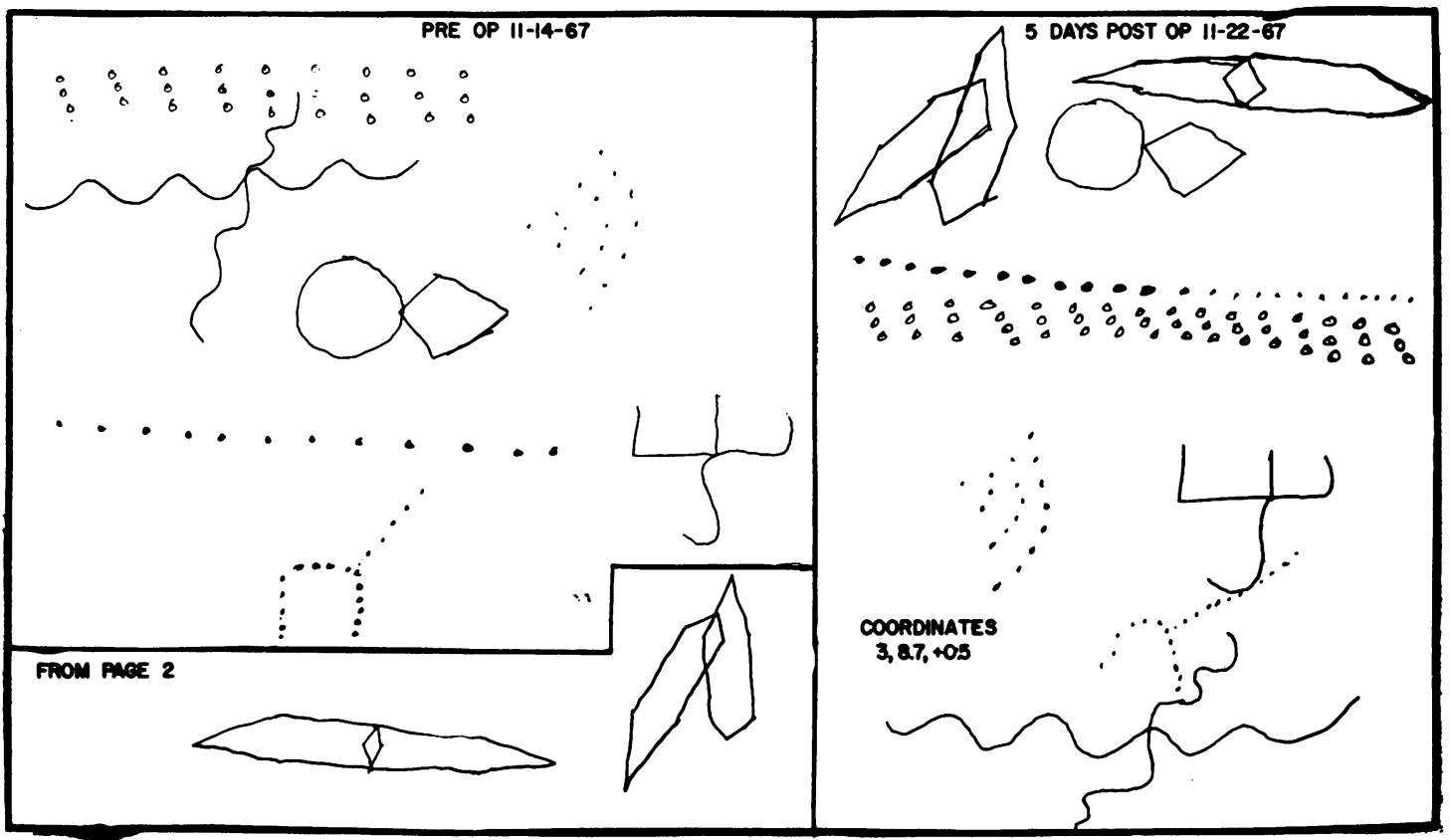

FIG. 1. (JB 187095.) Right thalamotomy. Bender Gestalt performance before and five days postoperatively. Note that the greater length of the page was oriented transversely for the preoperative test and vertically for the postoperative test. Perseveration is illustrated by the line of dots and loop figures which are repetitively drawn and extend across the entire page on the fifth postoperative day. Postoperative pressuring is evident from the increased blackness of some dots and loops. Retracing is evident in the hexagon figures (extreme top) in which some of the lines are redrawn. Collision is demonstrated by the overlapping of the dotted-hump and square-wave figures (lower half of illustration).

axis of a figure. Examples of perseveration, pressuring, retrace, and collision are given in Fig. 1.

The drawings done on the fifth postoperative day showed changes compared with their preoperative performance in 60 of 95 patients. For type of change there were no significant differences between lesions located in the centrum medianum nucleus and those located outside its borders in thalamic structures such as pulvinar, ventralis posterior, and ventralis oralis nuclei. Also, there were no significant differences between the right and left side except for collision which appeared to be associated primarily with the right side lesions ( $\chi^{2} 0.05$ level). In the 35 patients representing the 'no change' group, there were no significant differences for side or site of lesion. The more severe changes, like perseveration and collision, were not present after the second postoperative month, whereas, some of the less extreme changes like edging, pressuring, and expansion persisted beyond the first postoperative year.

Concerning right and left differences, it should be emphasized that the right side thalamic lesions induced changes in a significantly greater number of variables ( $t$ test 0.05 level).

There was correlation between the site of lesions and the number of variables impaired in a given patient (Fig. 2). Lesions located within the limits of the centrum medianum nucleus predominately implicated only a single variable (open circles; $\chi^{2}$ significant 0.01 level). The changes of greatest magnitude (simultaneous implication of three and four variables, black triangles) were, with one exception, all located peripheral to the centrum medianum nucleus $\left(\chi^{2} 0.05\right.$ level $)$.

PERCEPTION OF ILLUSIONS (NECKER CUBE) The 


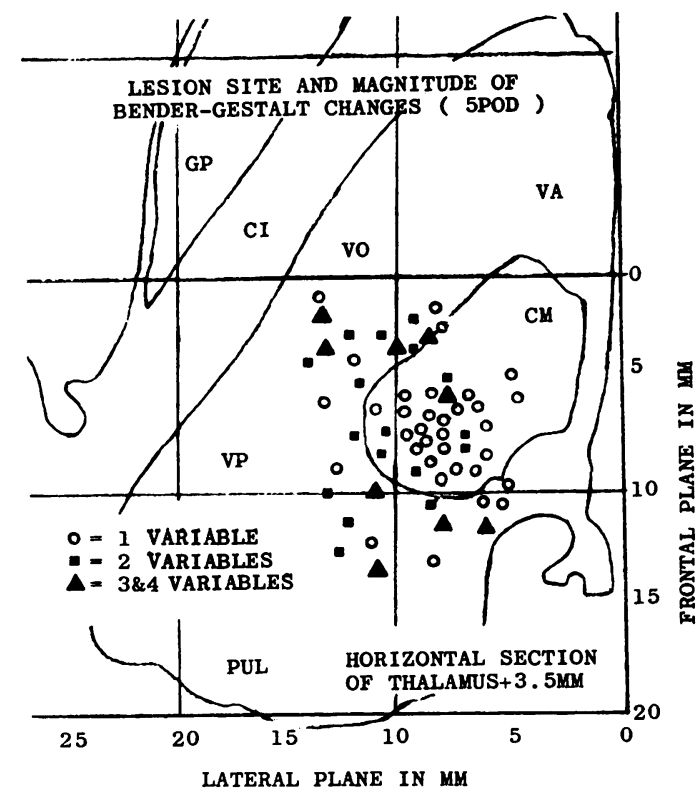

FIG. 2. Thalamic lesion site correlated with magnitude of Bender Gestalt change. Impairment of one variable, $\bigcirc$; impairment of two variables, $\square$; and impairment of either three or four variables, $\Delta$. $\mathrm{CM}$, centrum medianum; VA, ventralis anterior; VO, ventralis oralis; VP, ventralis posterior; PUL, pulvinar; CI, internal capsule; GP, globus pallidus.

number of apparent pattern reversals of a line drawing of a ' $1 / 2^{\prime} \times{ }^{\prime} 1 / 2^{\prime} \times{ }^{\prime} 3 / 8$ ' cube during a two minute period (Meldman, 1965) was determined for 60 patients pre-and postoperatively. It was found that decreased pattern reversal rates (open circles) predominated for lesions located in the more lateral portion of the centrum medianum nucleus and bordering thalamic nuclei (Fig. 3). Increased pattern reversal rates (solid black squares) were found for lesions located in the medial portion of the centrum medianum nucleus. For statistical analysis, using lateral plane $8.0 \mathrm{~mm}$ as representing the division between more lateral and more medial areas of the thalamus, the difference between direction of change and locus of lesion was significant at the 0.01 level $\left(\chi^{2}\right)$. There is the possibility that this is an artefact resulting from differences of lateralization, since two-thirds of the left thalamic lesions were medially located in the centrum medianum nucleus.

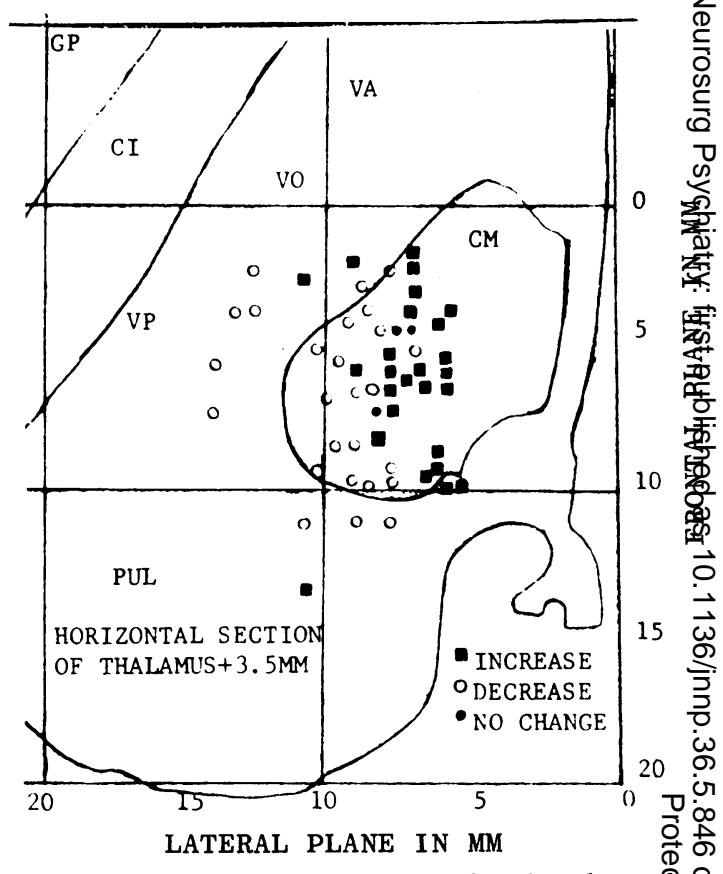

FIG. 3. Thalamic lesion site correlated with Neclege Cube reversal rate performance. Increased rates, decreased rates, $\bigcirc$; no change, $\bigcirc$. See Fig. 2 fo@ abbreviations.

Increased reversal rates persisted in some cases, or were further increased, as long as one year postoperatively. Decreased rates returne重 to preoperative ranges within six months.

COLOUR AND MOVEMENT (RORSCHACH TEST) The्द् percent colour and movement responses were determined from the Rorschach Psychodiagnostic Plates (Rorschach, 1921) in 53 patients. It should be noted that there was no significant difference in the mean number of responses preoperativel (18.6) and on the fifth postoperative day (17.8) Increased colour scores (solid black squareș, Fig. 4), predominated for lesions placed outside the limits of the centrum medianum nucleus, an decreased colour scores (open circles) for lesions within its boundaries ( $\chi^{2}$ significant 0.05 levelf Increased colour scores returned to preoperative levels within six months. Decreased scores weres seen as late as the second postoperative year. FQ̣5 movement responses there was no correlation between direction of change and lesion site. 

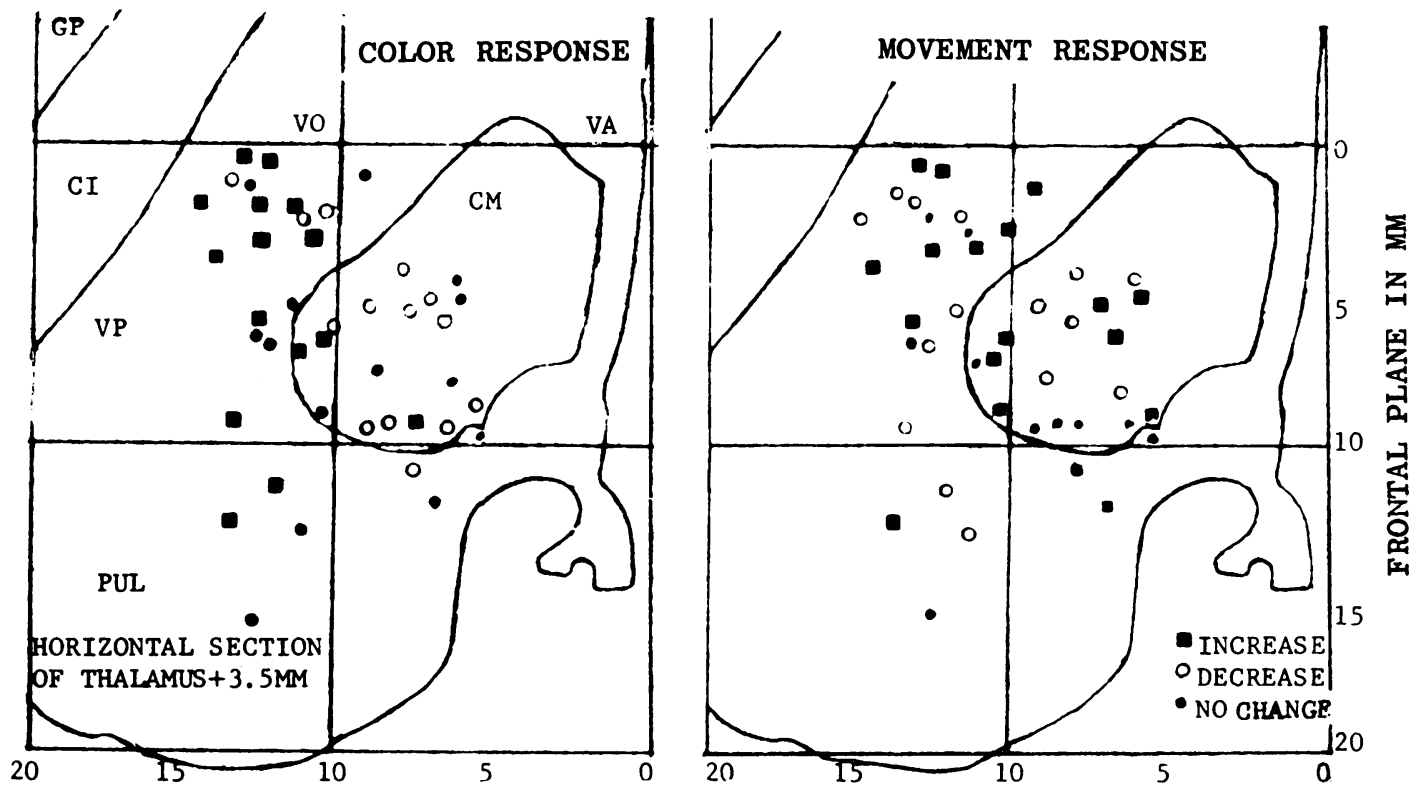

LATERAL PLANE IN MM

FIG. 4. Thalamotomy effects on the Rorschach test. Scattergrams of the colour and movement responses are presented in the left and right sides of the Figure respectively.
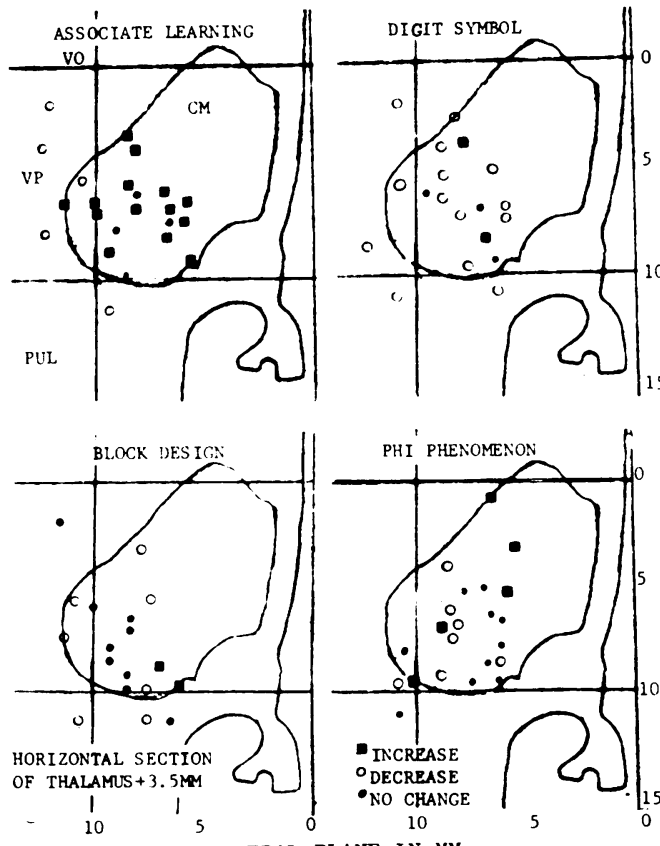

10

LATERAL PLANE IN MM

FIG. 5. Early thalamotomy effects on Associate learning, Digit symbol, Block design, and Phi phenomenon.
INTELLECTUAL FUNCTIONS The eight tests used to evaluate intellectual changes were as follows. (1) Similarities A test of verbal abstraction such as comparing the similarity between an axe and a saw. (2) Picture completion A test requiring identification of a missing part. (3) Digit symbol A test of speed and learning in matching numbers and symbols. (4) Block design A visual test of abstraction. These four tests are from the Wechsler Adult Intelligence Scale (WAIS) (Wechsler, 1955). (5) Associate learning A test of learning to associate paired words (taken from the Wechsler Memory Scale I, Wechsler, 1954). (6) Trail making $B$ (Reitan, 1955, 1958) A test which requires rapid searching for randomly placed alternating numbers and letters of the alphabet and joining them in ascending order. (7) Memory for designs (Graham and Kendall, 1960) A test which requires reproduction of geometric figures from memory. (8) Phi phenomenon (Graham, 1951) A test of illusory movement.

Test results are summarized in the scattergrams of Figs 5-8. Postoperative values are plotted according to lesion site and the direction 
ACUTE 5POD

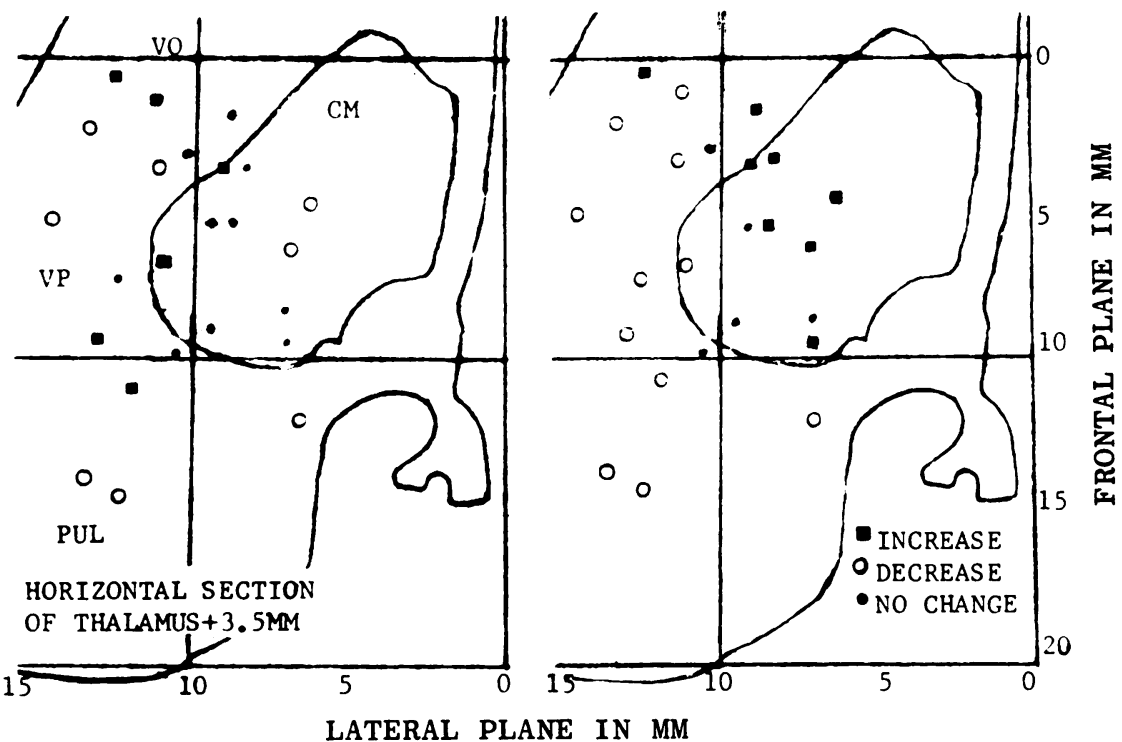

FIG. 6. Early and late thalamotomy effects on Similarities.

ACUTE 5POD

LATE $1 \frac{1}{2}-2$ YRS PO

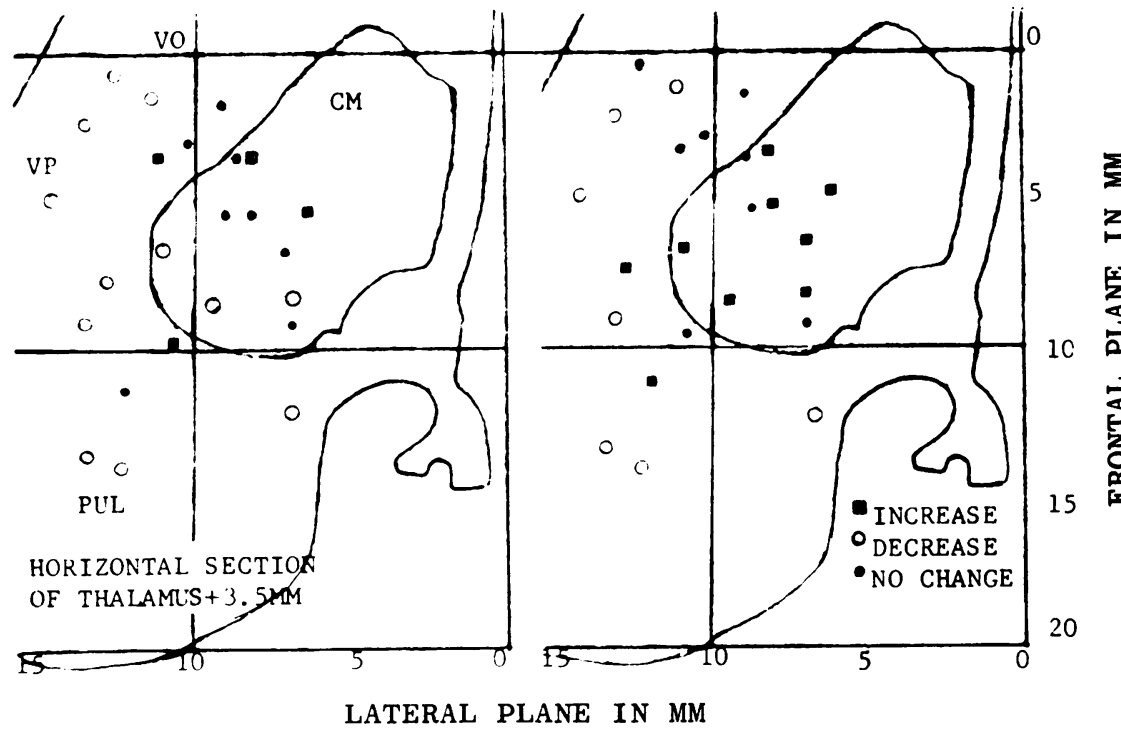

FIG. 7. Early and late thalamotomy effects on Trail making.

资 
ACUTE 5POD

LATE $1 \frac{1}{2}-2$ YRS PO
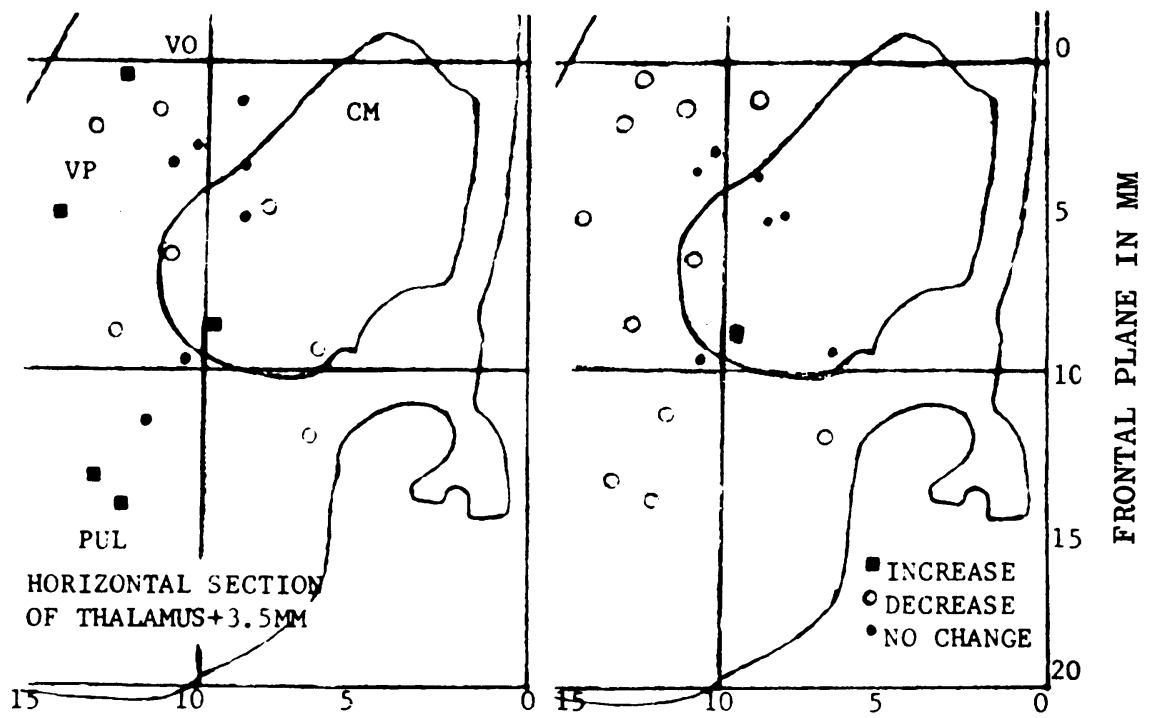

LATERAL PLANE IN MM

FIG. 8. Early and late thalamotomy effects on Memory for designs.

of change in relation to preoperative tests. It is to be noted that there were no significant differences in the direction of change between right and left side lesions. The following observations thus represent evaluation of combined right and left sides.

Associate learning (Fig. 5) Performance was improved in a significant number of patients five days postoperatively ( 0.06 level binomial expansion test). Further, the increased scores were for lesions located in the centrum medianum nucleus and decreased scores for lesions outside its limits (significant 0.01 level $\chi^{2}$ ). These changes were maintained postoperatively for as long as one year. Performance on Digit symbol was impaired in a significant number of patients $(0.004$ level binomial expansion test). Lesions within and outside the centrum medianum nucleus resulted in decreased scores. The depressed performance was temporary, with a return to preoperative levels within two months. For Block design and Phi phenomenon there were no significant directional changes following the lesions in the centrum medianum nucleus. Depressed scores persisted as long as one year postoperatively.
In scattergrams for Similarities (Fig. 6), Trail making (Fig. 7), and Memory for designs (Fig. 8) note the following which are of statistical significance: at one and a half to two years postoperatively there were a significant number of decreased scores for Similarities $\left(\chi^{2} 0.02\right)$ and Trail making $\left(\chi^{2} 0 \cdot 01\right)$, associated with lesions outside the centrum medianum nucleus. For patients with lesions within the nucleus, scores which were decreased five days postoperatively, had improved to a point above preoperative values. Another late postoperative effect was the decrement in the Memory for designs test (significant 0.01 level binomial expansion test). For the Picture completion test there were no directional or site differences which reached statistical significance.

\section{DISCUSSION}

In contrast with the centrum medianum, it appears that the ventralis posterior, pulvinar, and ventralis oralis nuclei of the thalamus are more involved in cognitive functions. Lesions placed within the centrum medianum result in relatively few deficits in cognitive skills. The 
simpler cognitive skills revealed minimal, if any, impairment after thalamotomy. No statistically significant changes were seen for Picture completion, which measures lower level conceptual abilities (Wechsler, 1955); for Block design, which is a task involving visual abstraction; and for Phi phenomenon, a basic flicker fusion experience. More complex cognitive skills revealed greater degrees of impairment after thalamotomy. For example, Digit symbol, Memory for designs, and Similarities are complex skills which underwent greater degrees of impairment.

Heightened response to colour on the Rorschach test (Piotrowski, 1937) and the decreased Necker Cube reversal rate (Meldman, 1965) have been associated with brain damage. It is of interest that impairments in those psychological tests were primarily associated with lesions outside the limits of the centrum medianum nucleus.

With respect to laterality, greater impairment on the Bender Gestalt test after right thalamic lesions is consistent with the findings for cortical lesions (McFie, Piercy, and Zangwill, 1950; McFie and Piercy, 1952; and Reitan, 1955, among others). There were no significant lateralization differences for any of the other tests, thus agreeing with the findings of Riklan and Levita (1969).

\section{REFERENCES}

Andy, O. J. (1966). Sensory-motor responses from the diencephalon. Electrical stimulation in man. Journal of Neurosurgery, 24, 612-620.
Andy, O. J., Jurko, M. F., and Sias, F. R., Jr. (1963). Sub-Zৃ thalamotomy in treatment of parkinsonian tremor. Journal of Neurosurgery, 20, 860-870.

Bender, L. (1946). Instructions for the Use of Visual Motor Gestalt Test. American Orthopsychiatric Association: Newo York.

Graham, C. H. (1951). Visual perception. In Handbook of Experimental Psychology, pp. 868-920. Edited by S. S. Stevens. Wiley: New York.

Graham, F. K., and Kendall, B. S. (1960). Memory-for Designs Test. Perceptual and Motor Skills: Missoula, Montana.

McFie, J., Piercy, M. F., and Zangwill, O. L. (1950). Visual spatial agnosia associated with lesions of the right cerebrale hemisphere. Brain, 73, 167-190.

McFie, J., and Piercy, M. F. (1952). Intellectual impairment? with localized cerebral lesions. Brain, 75, 292-311.

Meldman, M. J. (1965). The quantitative analysis of anxiety and depression. Psychosomatics, 6, 8-15.

Piotrowski, Z. (1937). The Rorschach inkblot method in $\vec{P}$ organic disturbances of the central nervous system Journal of Nervous and Mental Diseases, 86, 525-537.

Reitan, R. M. (1955). Certain differential effects of left an right cerebral lesions in human adults. Journal of Compara tive and Physiological Psychology, 48, 474-477.

Reitan, R. M. (1956). Trail Making Test. Mimeographed Indian University Medical Center: Indianapolis.

Reitan, R. M. (1958). Validity of the trail making test as indicator of organic brain damage. Perceptual and Mक्ठా Skills, 8, 271-276.

Riklan, M., and Levita, E. (1969). Subcortical Correlate of Human Behavior, Williams and Wilkins: Baltimore.

Rorschach, H. (1921). Psychodiagnostic Plates. Hubegrr Bern.

Schaltenbrand, G., and Bailey, P. (1959). Introductiont $\$$ Stereotaxis, with an Atlas of the Human Brain. Grune Stratton: New York.

Wechsler, D. (1954). Wechsler Memory Scale Form f.. Psychological Corporation: New York.

Wechsler, D. (1955). Wechsler Adult Intelligence Scals Manual. Psychological Corporation: New York.

Wechsler, D. (1958). The Measurement and Appraisal od Adult Intelligence, 4th ed. Williams and Wilkins: Baltimore 